\title{
Genetic counselling, BRCA1/2 status and clinico-pathologic characteristics of patients with ovarian cancer before 50 years of age
}

\author{
Mirjam Cvelbar, Marko Hocevar, Srdjan Novakovic, Vida Stegel, Andraz Perhavec, \\ Mateja Krajc
}

Institute of Oncology Ljubljana, Ljubljana, Slovenia

Radiol Oncol 2017; 51(2): 187-194.

Received 1 November 2016

Accepted 13 January 2017

Correspondence to: Assist. Prof. Mateja Krajc, M.D., Ph.D., Cancer Genetic Clinic, Institute of Oncology Ljubljana, Zaloska c. 2, SI-1000 Ljubljana, Slovenia. E-mail: mkrajc@onko-i.si

Disclosure: No potential conflicts of interest were disclosed.

Background. In Slovenia like in other countries, till recently, personal history of epithelial ovarian cancer (EOC) has not been included among indications for genetic counselling. Recent studies reported up to $17 \%$ rate of germinal BRCAl $/ 2$ mutation (gBRCA1/2m) within the age group under 50 years at diagnosis. The original aim of this study was to invite to the genetic counselling still living patients with $\mathrm{EOC}$ under 45 years, to offer $\mathrm{gBRCAl} / 2 \mathrm{~m}$ testing and to perform analysis of $\mathrm{gBRCAl} / 2 \mathrm{~m}$ rate and of clinico-pathologic characteristics. Later, we added also the data of previously genetically tested patients with EOC aged 45 to 49 years.

Patients and methods. All clinical data have to be interpreted in the light of many changes happened in the field of EOC just in the last few years: new hystology stage classification (FIGO), new hystology types and differentiation grades classification, new therapeutic possibilities (PARP inhibitors available, also in Slovenia) and new guidelines for genetic counselling of EOC patients (National Comprehensive Cancer Network, NCCN), together with next-generation sequencing possibilities.

Results. Compliance rate at the invitation was $43.1 \%$. In the group of 27 invited or previously tested patients with EOC diagnosed before the age of 45 years, five gBRCAl/2 mutations were found. The gBRCAl/2m detection rate within the group was $18.5 \%$. There were 4 gBRCA1 and 1 gBRCA2 mutations detected. In the extended group of 42 tested patients with EOC diagnosed before the age of 50 years, $14 \mathrm{gBRCA} / 2$ mutations were found. The gBRCA1/2m detection rate within this extended, partially selected group was 33.3\%. There were 11 gBRCA1 and 3 gBRCA2 mutations detected.

Conclusions. The rate of gBRCAl/2 mutation in tested unselected EOC patients under the age of 50 years was higher than $10 \%$, namely $18.5 \%$. Considering also a direct therapeuthic benefit of PARP inhibitors for BRCA positive patients, there is a double reason to offer genetic testing to all EOC patients younger than 50 years. Regarding clinical data, it is important to perform their re-interpretation in everyday clinical practice, because this may influence therapeutic possibilities to be offered.

Key words: ovarian cancer; BRCA1/2 gene; genetic counselling

\section{Introduction}

The frequency of germinal BRCA1/2 mutations in unselected patients with epithelial ovarian cancer (EOC) was found to be higher than $10 \%$, according to recent studies. ${ }^{1-5}$ Within the age group under 50 years at diagnosis, the reported frequency is even higher and it amounts up to $17 \%$, and within a subgroup of patients aged $40-49$ years the frequency amounts up to $24 \%$.,6

It is of utmost importance for optimal healthcare sistem in every country to have its own epidemio- 
logical data on frequency of germinal mutations of different hereditary cancers. Substantial research on BRCA1/2 germinal mutations in Slovenian population has been already done..$^{7-12}$ However, we haven't performed yet an analysis on the frequencies of BRCA1/2 mutations in ovarian cancer patients before the age of 50 years. In Slovenia like in other countries, till recently, personal history of epithelial ovarian cancer (EOC) has not been included among the indications for genetic counselling.

The original aim of this study was to include into the process of genetic counselling all living patients with epithelial ovarian cancer (EOC) diagnosed in the period 1999-2008 according to the data of the Slovenian National Cancer Registry who were younger than 45 years at the time of diagnosis and were treated at the Institute of Oncology Ljubljana. The process of genetic counselling included the possibility of genetic BRCA1/2 testing, with all possible clinical implications offered afterwards.

Our hypothesis was that the frequency of BRCA1/2 mutations in the tested patients would be higher than 10\%. Original study started in 2012. Later, we added also the data of previously genetically tested patients with EOC aged 45 to 49 years at the time of diagnoses who were diagnosed in the period 1999-2010.

All germinal BRCA1/2 mutation (gBRCA1/2m) positive patients were offered inclusion into the screening and prophylactic program for the highrisk group for breast cancer. In addition, since in the meantime the first PARP inhibitor was registered in European Union for therapy of BRCA positive serous ovarian cancers, in case of relapses mutation carriers were offered this treatment. Following new guidelines of SGO and National Comprehensive Cancer Network (NCCN), genetic counselling is offered now to all EOC patients in Slovenia. However, genetic testing is still restricted to EOC patients that were diagnosed with highgrade-serous EOC.

\section{Patients and methods}

\section{Ethical approval}

The study was approved by the National Medical Ethics Committee (201/02/1011).

\section{Patients accrual}

Data from 87 patients diagnosed with ovarian cancer (code C56 according to ICD-10) before the age of 45 years, in the period 1999-2008 and treated at the Institute of Oncology Ljubljana, were analyzed using the National Cancer Registry of Republic of Slovenia database. Patients with EOC and still alive were included. Two patients with borderline tumors and one patient with mixed ovarian cancer (carcinosarcoma) were included as well. Patients with germinal, stromal and some other rare nonepithelial ovarian cancers like primary ovarian lymphoma were excluded from the study.

With these inclusion and exclusion criteria, 57 patients were eligible to participate in the study. Since five of them have already undergone genetic counselling and BRCA testing, their anonymous data were included in the study with an extra approval of the National Medical Ethics Committee. The other 52 patients were invited by the letter to participate in the study. The invitation letter included patient information leaflet with all the data about the genetic counselling and testing and an invitation for genetic counselling at the Cancer Genetic Clinic of the Institute of Oncology Ljubljana. In patients under acute stress of an ongoing diagnostics or treatment, the invitation was postponed until the conclusion of such a process.

\section{Genetic testing (mutation screening, BRCA analysis)}

The DNA was isolated from peripheral blood using the DNA isolation kit (Quiagen, Hilden, Germany). Mutation screening was performed at the Institute of Oncology Ljubljana, Slovenia, and, for two samples, still at the Vrije Univerity Brussels, Belgium. Complete screening of all BRCA1/2 exons was performed, using method of multiplex ligation-dependent probe amplification analysis (MLPA; MRC Holland, Amsterdam, the Netherlands) for detection of large genomic deletions and insertions, and using high-resolution melting, denaturing gradient gel electrophoresis and direct sequencing methods already reported, for small mutations. ${ }^{8,9,11,12,13}$

Clinico-pathologic data of tested patients were collected from medical records following prepared study protocol. These included: family history of cancer including age at diagnosis in $1^{\text {st }}$ and $2^{\text {nd }}$ degree relatives, number of deliveries, hystologic type of ovarian cancer, tumor grade and disease stage. The old FIGO staging classification and hystologic type and grade classification were used for all patients since data accrual dated back to 1999 .

Due to $46.8 \%$ compliance rate and the small number of tested patients during the study, a de- 
TABLE 1. BRCAI/2 molecular diagnostics at patients with epithelial ovarian cancer under 50 years of age

\begin{tabular}{|c|c|c|c|c|c|c|}
\hline $\begin{array}{l}\text { Patient } \\
\text { code }\end{array}$ & $\begin{array}{c}\text { BRCA1 } \\
\text { HGVS c.DNA* }\end{array}$ & $\begin{array}{l}\text { BRCA1 } \\
\text { HGVS protein* }\end{array}$ & Type & $\begin{array}{c}\text { BRCA2 } \\
\text { HGVS C.DNA* }\end{array}$ & $\begin{array}{c}\text { BRCA2 } \\
\text { HGVS protein* }\end{array}$ & Type \\
\hline 1A01 & c. $5377 \mathrm{~A}>\mathrm{T}$ & p.(Lys 1793*) & Nonsense & & & \\
\hline $2 \mathrm{AOO}$ & c. $1067 A>G$ & p.(Gln356Arg) & Missense(UV) & & & \\
\hline $2 \mathrm{~A} 02$ & & & & $c .9117 \mathrm{G}>\mathrm{A}$ & p.(Pro3039Pro) & $\begin{array}{l}\text { Synonimus and } \\
\text { splicing }\end{array}$ \\
\hline $2 \mathrm{~A} 04$ & c. $181 \mathrm{~T}>\mathrm{G}$ & p.(Cys61Gly) & Missense & & & \\
\hline $3 \mathrm{~A} 01$ & & & & c. $3265 C>T$ & p. (Gln 1089*) & Nonsense \\
\hline $3 \mathrm{~A} 02$ & C. $181 \mathrm{~T}>\mathrm{G}$ & p.(Cys61Gly) & Missense & & & \\
\hline $3 \mathrm{~A} 03$ & c.844_850dupTCATTAC & p.(Gln284Leufs*5) & Frameshift & & & \\
\hline 3A04 & C.191G>A & p.(Cys64Tyr) & Missense & & & \\
\hline $4 \mathrm{~A} 04$ & & & & c. $5101 \mathrm{C}>\mathrm{T}$ & p.(Gln1701*) & Nonsense \\
\hline 4A05 & c.5266dupC & p.(GIn1756Profs*74) & Frameshift & & & \\
\hline
\end{tabular}

cision was reached of changing inclusion criteria to include also data of previously tested patients with ovarian cancer aged 45 to 49 years diagnosed in the period 1999-2008 and previously tested patients with ovarian cancer at age up to 49 years diagnosed during 2009-2010. The final number of patients included in the analysis of genetic and clinico-pathologic data was 42 patients, with 43 ovarian cancers (one patient had synchronously two different ovarian cancers).

\section{Statystical analysis}

Descriptive and bivariate statistics were used for analysis of the data. Due to small study group, exact tests (hi2 and t) were used. Statistical tests were performed with SPSS v.22 statistical software program.

\section{Results}

\section{Compliance}

Of the 52 invited patients, in one case patient's husband answered that the patient had recently died. Of the other 51 patients there were $22(43.1 \%)$ who decided for genetic counselling and were first counselled in 2012 and 2013. They all gave informed consent also for BRCA genetic testing. All tested patients received second-session genetic
TABLE 2. Family history of BRCA tested patients with EOC before age 45, diagnosed 1999-2008

\begin{tabular}{|c|c|c|c|c|}
\hline & & $\begin{array}{c}\text { gBRCAm + } \\
N=5\end{array}$ & $\begin{array}{c}\text { gBRCAm - } \\
\mathrm{N}=22\end{array}$ & $\begin{array}{l}\text { p (Fisher's } \\
\text { exact test) }\end{array}$ \\
\hline Family history(of any & Positive & 5 & 14 & \multirow{2}{*}{$p=0.280$} \\
\hline cancer at $1^{\text {st }}$ or $2^{\text {nd }}$ degree) & Negative & 0 & 8 & \\
\hline Family history of $1^{\text {st_ }}$ & Positive & 1 & 1 & \multirow{2}{*}{$p=0.342$} \\
\hline degreebreast cancer & Negative & 4 & 21 & \\
\hline Family history of $1^{\text {st_ }}$ & Positive & 2 & 0 & \multirow{2}{*}{$P=0.028$} \\
\hline degreeovarian cancer & Negative & 3 & 22 & \\
\hline
\end{tabular}

counselling afterwards when the result of genetic testing was known. There was no response from 17 patients; three patients postponed genetic counselling for several times and it became clear they are not sure about wanting it, therefore they were not included into the study. In four cases, the letter came back because the address was changed and patients were unretrievable. Five patients answered explicitly they did not want to participate.

\section{BRCA1/2 status analysis (mutation detection rate)}

In the group of 27 invited or previously tested patients with ovarian cancer diagnosed before the age of 45 years, 5 mutations were found. Mutation detection rate within the group therefore was $18.5 \%$. 
TABLE 3. Clinicopathologic characteristics at BRCA tested patients with EOC at age under 50 years

\begin{tabular}{|c|c|c|c|c|}
\hline & & $\begin{array}{c}\text { BRCA+ } \\
\text { Ovarian cancers } \\
N=15\end{array}$ & $\begin{array}{c}\text { BRCA- } \\
\text { Ovarian cancers } \\
N=28 \\
\end{array}$ & p \\
\hline Age at $1^{\text {st }}$ cancer & mean & 40.8 & 36.9 & 0.149 ( $t$ test) \\
\hline Age at the ovarian cancer & mean & 42.8 & 37.1 & 0.036 ( $t$ test) \\
\hline \multirow[b]{2}{*}{ Sequence of the ovarian cancer } & first & 11 & 23 & \multirow[b]{2}{*}{$0.037\left(\right.$ exact $\left.x^{2}\right)$} \\
\hline & second & 3 & 0 & \\
\hline \multirow{3}{*}{ Stage of the ovarian cancer (FIGO) } & $\|$ & $4(26.7 \%)$ & $2(7.1 \%)$ & \multirow{3}{*}{$0.055\left(\right.$ exact $\left.X^{2}\right)$} \\
\hline & III & 5 (33.3\%) & 7 (25.0\%) & \\
\hline & IV & $2(13.3 \%)$ & $2(7.1 \%)$ & \\
\hline \multirow{4}{*}{ Hystology Type of the Ovarian cancer } & serous & $6(40 \%)$ & $13(46.4 \%)$ & \multirow{4}{*}{$0.451\left(\right.$ exact $\left.x^{2}\right)$} \\
\hline & mucinous & 0 & $3(10.7 \%)$ & \\
\hline & endometrioid & $7(46.7 \%)$ & $7(25.0 \%)$ & \\
\hline & unknown & 0 & $1(3.6 \%)$ & \\
\hline \multirow{5}{*}{ Grade of the Ovarian cancer } & borderline & $1(6.7 \%)$ & $1(3.6 \%)$ & \multirow{5}{*}{$0.008\left(\right.$ exact $\left.x^{2}\right)$} \\
\hline & first & $1(6.7 \%)$ & $11(39.3 \%)$ & \\
\hline & second & $3(20.0 \%)$ & $9(32.1 \%)$ & \\
\hline & third & $10(66.7 \%)$ & $6(21.4 \%)$ & \\
\hline & unidentifiable & 0 & 1 (3.6\%) & \\
\hline
\end{tabular}

TABLE 4. Other cancers characteristics in BRCA tested patients with EOC at age under 50 years

\begin{tabular}{lcccc}
\hline & & $\begin{array}{c}\text { BRCA+ } \\
\text { N = 14 }\end{array}$ & $\begin{array}{c}\text { BRCA- } \\
\text { N=28 }\end{array}$ & p \\
\hline Previous invasive & Yes & 2 & 0 & $\mathrm{P}=0.106\left(\right.$ exact $\left.X^{2}\right)$ \\
breast cancer & No & 12 & 28 & \\
Later invasive breast & Yes & 3 & 0 & $\mathrm{P}=0.032\left(\right.$ exact $\left.X^{2}\right)$ \\
cancer & No & 11 & 28 & \\
Occurrence of DCIS & Yes & 0 & 2 & $\mathrm{P}=0.545\left(\right.$ exact $\left.X^{2}\right)$ \\
breast cancer & No & 14 & 26 & \\
$\begin{array}{l}\text { Concurrent } \\
\text { Endometrial Cancer }\end{array}$ & Yes & 0 & 5 & $\mathrm{P}=0.151\left(\right.$ exact $\left.X^{2}\right)$ \\
(with ovarian one) & No & 14 & 23 & \\
\hline
\end{tabular}

There were four BRCA1 and one BRCA2 mutations (Table 1).

In the extended group of 42 tested patients with ovarian cancer diagnosed before the age of 50 years (during the period 1999-2010), 14 mutations were found. Mutation detection rate within this extended, partially selected group was $33.3 \%$.

There were 11 BRCA1 and three BRCA2 mutations (Table 1).

\section{Clinicopathologic results}

Family history of a presence of any cancer in $1^{\text {st }}$ or $2^{\text {nd }}$ degree relative didn't show significant difference in the rate between gBRCA1/2m positive and negative group. As well, a family history of $1^{\text {st }}$ degree breast cancer was of similar rate between the groups. There was significantly higher rate of $1^{\text {st }}$ degree ovarian cancer in family history of gBRCAm $1 / 2$ positive patients (Table 2 ).

Mean age at the ovarian cancer diagnosis was significantly higher at gBRCA $1 / 2 \mathrm{~m}$ positive patients (42.8 years vs. 37.1 years; $\mathrm{p}=0.036$ ). There was no statistically significant difference in mean age at the diagnosis of first cancer (Table 3).

Analysis of the sequence of cancers showed that the rate of ovarian cancer as the second cancer was significantly higher in gBRCA1/2m positive group.

Regarding stage of ovarian cancer, there was a trend of higher rate of the first stage in gBRCA1/2m negative group $(60.7 \%$ vs. $26.7 \%$ in gBRCA $1 / 2 \mathrm{~m}$ positive; $\mathrm{p}=0.055)$.

In ovarian cancer hystology type there was no statistically significant difference and the rate of serous type was nearly the same $(40 \%$ in gBRCA $1 / 2 \mathrm{~m}$ positive patients $v s .46 \%$ in negative ones). There was no mucinous type in gBRCA $1 / 2 \mathrm{~m}$ positive group. Clear-cell type was present only in one case 
of mixed carcinoma. Carcinosarcoma case did not make part of gBRCA1/2m positive group.

In ovarian cancer grade there was significantly higher rate of high-grade (G2 and G3) cancers in gBRCA1/2m positive group $(66.7 \%$ vs. $21.4 \%$ in negative group; $\mathrm{p}=0.008)$. There was also a case of borderline ovarian cancer in gBRCA1/2m positive group. This borderline ovarian cancer of stage I was concomitant with contralateral grade I and stage I ovarian cancer. Therefore, there were 43 cancers diagnosed in 42 patients (Table 3 ).

Tubal contralateral serous malignant changes defined as synchronous contralateral tubal cancer stage III were found in one patient. They were defined as second primary cancer because ovarian cancer was endocystical (endophitic growth in serous cystadenoma). Patient was gBRCA1/2m positive.

Analysis of the other cancers diagnosed in the same patients showed that there was at least a trend (considering No of patients, and significant difference considering No of ovarian cancers) of higher rate of previous invasive breast cancer in gBRCA1/2m positive group. As well, there was significantly higher rate of later invasive breast cancer in gBRCA1/2m positive group. The rate of DCIS of the breast showed no statistical difference between the groups (Table 4).

Concurrent endometrial cancer was found in 5 out of 28 gBRCA1/2m negative patients and in $\mathrm{O}$ out of 14 positive patients, but the difference was not statistically significant $(\mathrm{p}=0.151)$.

\section{Discussion}

\section{Genetic counselling and testing}

Compliance of the OC patients invited to genetic counselling was similar to our previous study. ${ }^{10} \mathrm{It}$ would've been probably higher if there had been a direct therapeutic benefit of testing already present. At the time when our study started, PARP inhibitors have not been yet registered and used in standard therapy of OC patients. Therefore direct benefit of testing consisted in surveillance for eventual second primary breast cancer or in its prevention in gBRCA1/2 positive OC patients. Indirect benefit was present for patients' relatives.

Pal et al. ${ }^{1}$ reported a higher compliance than ours: $64 \%$ vs. $43.1 \%$, respectivelly. Both studies were performed in a period before olaparib therapy was approved. We may speculate that the reason for the difference might have been the way of inviting the patients, which is not described in their paper. Namely, one can suppose that the invitation comming from medical doctor directly involved in therapy process is more efficient than the invitation comming from Cancer Genetic Clinic team. Indeed, our latest data from October 2014 show much higher compliance rate of $82.5 \%$, since genetic councelling and testing was performed for therapeutic reasons and patients were reffered to Cancer Genetic Clinics by their medical oncologists. ${ }^{14}$

Mutation rate of $18.5 \%$ (5/27) within the group of unselected EOC patients under 50 years of age is in accordance with studies already mentioned and with our hypothesis. In accordance are also results of Australian Ovarian Cancer Study Group, published after the beginning of our study, which found gBRCA $1 / 2 \mathrm{~m}$ rate of $22.2 \%$ in EOC patients diagnosed before the age of 50 years. ${ }^{15}$ As someone could expect it is higher than the rate found in most of population-based studies with EOC patients unselected for the age. ${ }^{16}$

We are aware of limitations of our small study group as a consequence of several factors, above all of low incidence of EOC under the age of 50 years and of small population of our country. Therefore, it was not possible to perform a subanalysis of mutation rate of the EOC patients aged 40-49 years and compare results to recently published large Canadian population-based study which found mutation rate of $24.0 \%{ }^{6}$ Nevertheless it is noteworthy that one of $\mathrm{gBRCA} 1 / 2 \mathrm{~m}$ positive patients in our study was only 24 years old at EOC diagnosis. In the European multicentric study of Lakhani et al. there was no such case of gBRCA1/2 positive EOC patient under 30 years age found. Therefore, it is rare, but not impossible.

The gBRCA1/2 mutation rate of $33.3 \%$ for our larger, combined and partly selected EOC group under the age of 50 years is not representative for the entire population of EOC patients under the age of 50 years in Slovenia, because 20 out of 42 patients were tested on the basis of BRCAPRO calculation and not on the basis of EOC diagnosis under the age of 50 years.

Regarding the type of mutations no new slovenian mutations and also no founder mutations were found. All mutations found have already been described. ${ }^{11}$

\section{Clinicopathologic features}

Family history of gBRCA1/2m positive patients not surprisingly had higher $1^{\text {st }}$ degree ovarian cancer rate. With larger sample we would expect also higher $1^{\text {st }}$ degree breast cancer history rate, according to published data. ${ }^{1,3,4}$ 
The mean age of gBRCA1/2m positive patients (42.8 years) was higher than that of negative ones (37.1 years). Eleven out of fourteen positive patients were $40-49$ years old. This surprising result is however in accordance with Canadian study in which the prevalence of mutations was particularly high among women in their forties. ${ }^{6}$ Contrary, Danish study found the highest gBRCA1/2 mutation rate $(23 \%)$ in EOC patients under the age of 40 years. ${ }^{4}$ The large European multicentric study of 207 gBRCA1/2m positive EOC patients found not a single case at the age below 30 years, while there were $13 \mathrm{gBRCA} 1 / 2 \mathrm{~m}$ negative EOC patients in this very young age group. In age groups of 30-39 and 40-49 years old there were more patients with, than without gBRCA1/2 mutation (20 vs. 16 and 68 vs. 49). In patients older than 50 years sporadic cases prevailed. ${ }^{17}$ Interestingly the youngest patient with gBRCA $1 / 2 \mathrm{~m}$ in our study was only 24 years old at the time of OC diagnosis.

EOC was significantly more often a second primary cancer, after the breast cancer which had developed earlier, in the group of gBRCA $1 / 2 \mathrm{~m}$ positive in comparison to gBRCA $1 / 2 \mathrm{~m}$ negative patients (2/12 compared to 0/28). This is in accordance with published data on double primary breast and ovarian cancer. ${ }^{10,18,19}$ In a large international pathology study of CIMBA consortium published in 2012 it was found that 415 of $1129(36.8 \%)$ gBRCA1/2m positive EOC patients had developed breast cancer before developing ovarian cancer. ${ }^{20}$

Higher grade of EOC in patients with gBRCA1/2 mutation observed in our study is in accordance with most of the published data. ${ }^{17,20}$

In accordance with published data is also a higher stage trend in $\mathrm{gBRCA} 1 / 2 \mathrm{~m}$ positive group observed in our study. ${ }^{15,21}$

The most unexpected finding of our study is high rate of endometroid type of EOC in gBRCA1/2m positive group $(46.7 \%)$. This seems in contrast with current concepts of tubal origin and of high-grade serous type of »ovarian" cancer in gBRCA $1 / 2 \mathrm{~m}$ positive patients. ${ }^{22}$ It is also in contrast with our previous results of a pilot study (10) where 8/12 (66.7\%) gBRCA1/2m positive ovarian cancers were serous and only 2/12 (16.7\%) were endometrioid ones. But interestingly, high rate of endometrioid type was noted in unselected OC patients in Slovenia also in the past. ${ }^{23,24}$ It was argued that this could be attributed to different histopathological criteria and interpretation.

Internationally, the problem of histopathological interpretation was specifically adressed in a large European study published in 2004. ${ }^{17}$ Aware of the problem of interobserver variation and of particular difficulty when a lesion is high grade, they attempted to minimise the effects of interobserver variability. In so doing, they found that even if the frequency of serous EOC was higher among gBRCA1m carriers compared with controls, it accounted for only $40 \%$ of EOC, and consecutivelly the frequencies of other (but mucinous) histology types were higher than in previous reports, with endometrioid type accounting for $33 \%$ in gBRCA1m carriers, $29 \%$ in gBRCA2m carriers and $33 \%$ in gBRCAm negative EOC patients. Also clear cell EOC frequencies were similar in carriers than in controls.

In the light of these data, the rates of various histologic types found in our study are more correspondent to international data of that period.

Further decisive highlights on relationship between serous and endometrioid type of EOC are comming from a series of studies with molecular approach, making research in gene expression profiling; the results show that high-grade serous type EOC and high-grade endometrioid EOC are molecularly similar. ${ }^{25,26}$ Therefore, it emerges that morfological similarity has its basis in molecular similarity of these two, only appearantly different histologic subtypes of EOC. Indeed, Alsop et al. report that increasingly, high-grade endometrioid EOC are being reclassified as high-grade serous EOC. ${ }^{15}$

In our study, four out of seven endometrioid gBRCA1/2m positive EOC were high-grade (G3) and therefore morfologically and molecularly similar to serous high-grade type. Other three endometrioid gBRCA1/2m positive EOC were borderline, low-grade (G1) and medium grade (G2). Therefore, even if high-grade and also medium-grade endometrioid EOC case would've been reclassified today in high-grade serous EOC, there remains a case of $\mathrm{gBRCA} 1 / 2 \mathrm{~m}$ positive patient with borderline and low-grade endometrioid EOC which can not be reclassified.

It's known that in general, $15-20 \%$ of endometrioid EOC is associated with carcinoma of the endometrium. ${ }^{22}$ In our study there was no such case found in gBRCA1/2m positive EOC patients, but there were 5 cases in gBRCA1/2m negative patients. We found no specific data in the literature with regard to gBRCA1/2 mutation in patients with concurrent (synchronous) endometrial and ovarian cancer. However, a case of germline mutation in another tumor supressor gene RAD51D was recently described in such a patient. ${ }^{27}$

Concurrent primary contralateral invasive tubal cancer was found in one gBRCA1/2m positive EOC 
patient. STIC (serous tubal intraepithelial carcinoma) as a precursor of serous »ovarian « cancer was not adressed in present study, because a change of concepts and of histologic practice occured only a few years ago and therefore STIC has not yet been a part of standardised histopathologic report in EOC patients in the period analysed.

\section{Conclusions}

The rate of gBRCA1/2 mutation in tested EOC patients under the age of 50 years is higher than 10\% (18.5\%). Considering also a direct therapeuthic benefit of PARP inhibitors for BRCA positive patients, there is a double reason to offer genetic testing to all EOC patients younger than 50 years.

Positive patients for gBRCA1/2m can be younger than 30 years so even very young patients can not be excluded from gBRCA $1 / 2 \mathrm{~m}$ testing.

Almost half of the gBRCA $1 / 2 \mathrm{~m}$ positive patients has been diagnosed as having endometrioid histologic type of EOC. It is important to consider for individual patient how far ago the hystologic diagnosis was made, since high-grade endometrioid type, on the basis of recent molecular studies, is more and more often reclassified to high-grade serous type.

However, among our gBRCA1/2m positive patients, there was also a case of concurrent lowgrade endometrioid ovarian tumor and contralateral borderline endometrioid EOC, so endometrioid EOC in positive patients is not only a question of overlapping of high-grade endometrioid and high-grade serous EOC. Therefore we must consider for gBRCA1/2 testing all patients with EOC younger than 50 years and not only serous-type EOC patients.

\section{Acknowledgement}

This work was supported by the grant P3 0352 from the Ministry of Education, Science and Sport of the Republic Slovenia.

\section{References}

1. Pal T, Permuth-Wey J, Betts JA, Krischer JP, Fiorica J, Arango H, et al. BRCA1 and BRCA2 mutations account for a large proportion of ovarian carcinoma cases. Cancer 2005; 104: 2807-16. doi: 10.1038/bjc.2012.483

2. Brozek I, Ochman K, Debniak J, Morzuch L, Ratajska M, Stepnowska M, et al. High frequency of BRCA1/2 germline mutations in consecutive ovarian cancer patients in Poland. Gynecol Oncol 2008; 108: 433-7. doi: 10.1016/j. ygyno.2007.09.035
3. Ramus SJ, Gayther SA. The contribution of BRCA1 and BRCA2 to ovarian cancer. Mol Oncol 2009; 3: 138-50. doi: 10.1016/j.molonc.2009.02.001

4. Soegaard M, Kruger Kjaer S, Cox M, Wozniak E, Hǿgdall E, Hǿgdall C, et al. BRCA1 and BRCA2 mutation prevalence and clinical characteristics of a population-based series of ovarian cancer cases from Denmark. Clin Cancer Res 2008; 14: 3761-7. doi: 10.1158/1078-0432

5. Trainer AH, Meiser B, Watts K, Mitchell G, Tucker K, Friedlander M. Moving toward personalized medicine: treatment-focused genetic testing of women newly diagnosed with ovarian cancer. Int J Gynecol Cancer 2010; 20: 704-16. doi: 10.1111/IGC.0b013e3181dbd1a5

6. Zhang S, Royer R, Li S, McLaughlin JR, Rosen B, Risch HA, et al. Frequencies of BRCA1 and BRCA2 mutations among 1342 unselected patients with invasive ovarian cancer. Gynecol Oncol 2011; 121: 353-7. doi: 10.1016/j. ygyno.2011.01.020

7. Krajc M, De Greve J, Goelen G, Teugels E. BRCA2 founder mutation in Slovenian breast cancer families. Eur J Hum Genet 2002, 10: 879-82. doi: 10.1038/sj.ejhg.5200886

8. Krajc M, Teugels E, Žgajnar J, Goelen G, Bešić N, Novaković S, et al. Five recurrent BRCA1/2 mutations are responsible for cancer predisposition in the majority of Slovenian breast cancer families. BMC Med Genet 2008; 9: 83. doi: 10.1186/1471-2350-9-83

9. Stegel V, Krajc M, Žgajnar J, Teugels E, De Greve J, Hočevar M, et al. The occurence of germline BRCA1 and BRCA2 sequence alterations in Slovenian population. BMC Med Genet 2011, 12: 9. doi: 10.1186/1471-2350-12-9

10. Cvelbar M, Hočevar M, Vidmar G, Teugels E. BRCA1/2 status and clinicopathologic characteristics of patients with double primary breast and ovarian cancer. Neoplasma 2011; 58: 198-204. doi: 10.4149/neo_2011_03_198

11. Novaković S, Milatović M, Cerkovnik P, Stegel V, Krajc M, Hočevar M, et al. Novel BRCA1 and BRCA2 pathogenic mutations in Slovene hereditary breast and ovarian cancer families. Int J Oncol 2012, 41: 1619-27. doi: 10.3892/ ijo.2012.1595

12. Krajc M, Zadnik V, Novaković $S$, Stegel $V$, Teugels $E$, Bešič $N$, et al. Geographical distribution of Slovenian BRCA1/2 families according to family origin: implications for genetic screening. Clin Genet 2014; 85: 59-63. doi: $10.1111 /$ cge.12119

13. Bešić N, Černivc B, de Grève J, Lokar K, Krajc M, Novaković $\mathrm{S}$, et al. BRCA2 gene mutations in Slovenian male breast cancer patients. Genet Test 2008; 12: 203-9. doi: 10.1089/gte.2007.0071

14. Krajc M, Blatnik A, Stegel V, Cerkovnik P, Škof E, Novaković S. BRCA status in ovarian cancer patients predicts therapeutic approach - first results. In: Writzl K, Teran N, Maver A, editors. $6^{\text {th }}$ symposium of the Slovenian Association of Medical Genetics. Gene editing technology: applications and societal implications. Book of abstracts; 2016 Apr 22; Ljubljana, Slovenia. Ljubljana: Slovenian Association of Medical Genetics, Slovenian Medical Association; 2016. p. 19

15. Alsop K, Fereday S, Meldrum C, deFazio A, Emmanuel C, George J, et al. BRCA mutation frequency and patterns of treatment response in BRCA mutation-positive women with ovarian cancer: a report from the Australian Ovarian Cancer Study Group. J Clin Oncol 2012; 30: 2654-63. doi: 10.1200/ JCO.2011.39.8545

16. Girolimetti G., Perrone AM, Santini D, Barbieri E, Guerra F, Ferrari S, et al. BRCA-associated ovarian cancer: From molecular genetics to risk management. Biomed Res Int 2014; 2014: 787143. doi: 10.1155/2014/787143

17. Lakhani SR, Manek S, Penault-Lorca F, Flanagan A, Arnout L, Merrett S, et al. Pathology of ovarian cancers in BRCA1 and BRCA2 carriers. Clin Cancer Res 2004; 10: 2473-81. doi: 10.1158/1078-0432.CCR-1029-3

18. Fishman A, Dekel E, Chetrit A, Lerner-Geva L, Bar-Am, Deck D, et al. Patients with double-primary tumors in the breast and ovary - clinical characteristics and BRCA1-2 mutations status. Gynecol Oncol 2000; 79: 74-8. doi: 10.1006/ gyno. 2000.5895

19. Schorge JO, Mahoney NM, Miller DS, Coleman RL, Muller CY, Euhus DM, et al. Germline BRCA1-2 mutations in Non-Ashkenazi families with double primary breast and ovarian cancer. Gynecol Oncol 2001; 83: 383-7. doi: 10.1006/gyno.2001.6431

20. Mavaddat N, Barrowdale D, Andrulis IL, Domchek SM, Eccles D, Nevanlinna $\mathrm{H}$, et al. Pathology of breast and ovarian cancers among BRCA1 and BRCA2 mutation carriers: Results from the Consortium of Investigators of Modifiers of BRCA1/2 (CIMBA). Cancer Epidemiol Biomarkers Prev 2012; 21: 134-47. doi: 10.1158/1055-9965.EPI-11-0775 
21. Boyd J, Sonoda Y, Federici MG, Bogomolniy F, Rhei E, Maresco DL, et al. Clinicopathologic features of BRCA-linked and sporadic ovarian cancer JAMA 2000; 283: 2260-5.

22. Prat J. Ovarian carcinomas: five distinct diseases with different origins, genetic alterations, and clinicopathologic features. Virchows Arch 2012; 460: 237-49. doi: 10.1007/s00428-012-1203-5

23. Rakar S, Štolfa A, Kovačič J. Ovarijski karcinom: današnje stanje in perspektive. Zdrav Vestn 1994; 63: 569-71.

24. Cvelbar M, Kralj B. Zgodnje odkrivanje epitelnega karcinoma jajčnika. Zdrav Vestn 2001; 81-4.

25. Schwartz DR, Kardia SLR, Shedden KA, Kuick R, Michailidis G, Taylor JMG, et al. Gene expression in ovarian cancer reflects both morphology and biological behavior, distinguishing clear cell from other poor-prognosis ovarian carcinomas. Cancer Res 2002; 62: 4722-9.

26. Tothill RW, Tinker AV, George J, Brown R, Fox SB, Lade S, et al. Novel molecular subtypes of serous and endometrioid ovarian cancer linked to clinical outcome. Clin Cancer Res 2008; 14: 5198-208. doi: 10.1158/1078-0432

27. Wickramanayake A, Bernier G, Pennil C, Casadei S, Agnew KJ, Stray SM, et al. Loss of function germline mutations in RAD51D in women with ovarian carcinoma. Gynecol Oncol 2012; 127: 552-5. doi: 10.1016/j.ygyno.2012.09.009 